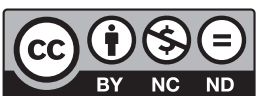

Estudos Teológicos foi licenciado com uma Licença Creative Commons Atribuição - NãoComercial - SemDerivados 3.0 Não Adaptada

http://dx.doi.org/10.22351/et.v59i1.3258

\title{
FicÇão e CONSTRUÇão DE IDENTIDAde nos Atos Apócrifos dos Apóstolos ${ }^{1}$
}

\author{
Fiction and identity construction in \\ Apocryphal Acts of the Apostles
}

\begin{abstract}
Kenner Roger Cazotto Terra ${ }^{2}$
Resumo: Os Atos Apócrifos dos Apóstolos são textos escritos nos séculos II e III, nos quais são narradas, de maneira heroica, as aventuras de André, Paulo, Tomé e outros apóstolos. Essas obras representam a preservação das memórias dos cristianismos dos primeiros três séculos e possuem muitos temas e gêneros comuns à tradição literária greco-romana. Como narrativas ficcionais de construção discursiva de mundo, os Atos Apócrifos demonstram as expectativas das comunidades cristãos das origens, a maneira como pensavam a realidade e suas relações sociais, os pactos comunicativos, compreensão de si no mundo greco-romano e interpretações topográficas, por vezes perpassadas por geografias míticas. Por isso os Atos Apócrifos dos Apóstolos tornam-se fontes indispensáveis para compreensão científica dos cristianismos das origens. Assim, superando o preconceito canônico, observaremos através desses textos a maneira como as comunidades cristãs constroem nessas narrativas suas identidades e ficcionam o mundo do Mediterrâneo, muitas vezes subvertendo-o e refazendo os discursos do Império Romano.
\end{abstract}

Palavras-chave: Atos Apócrifos dos Apóstolos. Ficção. Construção de identidade. Cristianismos das origens.

Abstract: The Apocryphal Acts of the Apostles are texts written in the 2nd and 3rd centuries, in which the adventures of Andrew, Paul, Thomas and other apostles are narrated in a heroic way. These texts represent the preservation of the memoirs of the Christianity of the first three centuries and have many themes and genres common to the Greco-Roman literary tradition. As fictional narratives and discursive world-building, the Apocrypha Acts demonstrate the expectations of Christian communities of the origins, the way they thought the reality and their social relations, their communicative pacts, self-understanding in the Greek-Roman world and sometimes topographical interpretations pervaded by mythical geographies. Hence, the Apocryphal Acts of the Apostles become indispensable sources for a scientific understanding of the Christianity

1 O artigo foi recebido em 05 de fevereiro de 2018 e aprovado em 11 de junho de 2018 com base nas avaliações dos pareceristas ad hoc.

2 Doutor em Ciências da Religião pela Universidade Metodista de São Paulo. Professor na Faculdade Unida de Vitória, Espírito Santo. Contato: kenner@faculdadeunida.com.br 
of the origins. Thus, overcoming the canonical prejudice, we will observe, through the Apocryphal Acts, the way in which the Christian communities constructed their identities in those narratives and fictionalized the world of the Mediterranean, often subverting it and remaking the discourses of the Roman Empire.

Keywords: Apocryphal Acts of the Apostles. Fiction. Identity construction. Early Christianity.

\section{Introdução}

Os Atos Apócrifos dos Apóstolos são romances, semelhantes aos greco-romanos e judaicos, nos quais personagens apostólicos são figuras heroicas, apresentadas com potencialidades sobrenaturais, taumatúrgicas, enviados aos diversos lugares do Mediterrâneo, muitas vezes passando por peripécias e enfrentando lideranças locais e imperiais. Esses são escritos no segundo e terceiro séculos, inseridos no contexto de longa extensão geográfica (Grécia, Ásia Menor, Síria). Cada texto exibe um enredo similar, apresentando as aventuras, pregações e morte de cada apóstolo. ${ }^{3}$ Eles revelam, em muitos casos, aventuras pitorescas de Pedro, André, Paulo, Tomé, Filipe e outros heróis das memórias dos cristianismos dos primeiros três séculos.

Como narrativas ficcionais de construção discursiva de mundo, os Atos Apócrifos demonstram as expectativas das comunidades cristãs das origens, a maneira como pensavam a realidade e suas relações sociais, os pactos comunicativos, suas memórias do dizer, compreensão de si no mundo greco-romano e interpretações topográficas, por vezes perpassadas por geografias míticas.

Os Atos Apócrifos são importantes para a compreensão das primeiras comunidades cristãs e suas propagandas, porque revelam o poder dos personagens que carregam a fé e sua relação com seu mundo. As curas, nessa perspectiva, são realizadas como demonstração da autoridade da sua religião. Podemos perceber claramente o tom proclamatório em Atos de João. ${ }^{4} \mathrm{Na}$ narrativa, João e seu deus são como fonte de esperança para o pretor de uma grande cidade, o que revela a força do apóstolo e de sua divindade no contexto do Império. O tom triunfalista perpassa claramente os Atos, especialmente na capacidade de seus personagens principais se livrarem da morte, realizarem proezas, vencerem o poder de bebidas venenosas etc. Em Atos de André e Matias ${ }^{5}$, depois de serem divididas as regiões para onde iriam os apóstolos, Matias é escolhido para ser enviado às terras dos canibais, os quais tomavam os es-

3 PERKINS, Judith. The Suffering Self: Pain and Narrative Representation in the Early Christian Era. London; New York: Routledge, 1995. p. 124.

4 "E nos aproximando da cidade e Lycomedes, um homem robusto, que era pretor de Éfeso, caindo aos pés de João, disse-lhe: tu és João? O Deus que tu pregas tem te enviado para ajudar minha esposa que está paralisada e deitada há sete dias, sem poder ser curada" (Atos de João 18). Cf. SCHNEEMELCHER, W. New Testament Apocrypha. Kentucky: Westminster John Knox, 1992. v. 2, p. 172.

5 Há uma discussão sobre a relação de Atos de André e Matias e os Atos de André. Neste trabalho, trataremos os Atos de André e Matias como obra autônoma e posterior. Cf. MACDONALD, Dennis R. The Actos of Andrew and Mathias and the Actos of Andrew. In: Semeia, n. 38, p. 9-25, 1986. 
trangeiros, arrancavam seus olhos, davam uma bebida entorpecente, um líquido mágico, e prendiam para serem devorados. Contudo, no texto, com Matias a bebida não fez efeito, lembrando a narrativa da comissão de Marcos 16. Pelo contrário, ele não é embriagado e, depois de orar, tem uma experiência de revelação, através da qual um personagem, chamado de Salvador, que se refere ao Cristo ressurreto, anuncia-lhe a libertação em vinte e sete dias por meio do envio de André.

Além disso, uma área fascinante dos estudos nos Atos Apócrifos é como esses textos narrativizam tradições que lhes antecedem. ${ }^{6}$ Como bem explica Paulo Nogueira, "essas narrativas se configuram, junto com os evangelhos, como os mais antigos testemunhos de literatura que preserva memórias populares do cristianismo"7. Por isso essa literatura é rica fonte de tradições e lendas a respeito dos apóstolos, assim como de temas, gêneros e liturgias, tais como o hino da pérola, nos Atos de Tomé, e o hino ou dança de Jesus, nos Atos de João.

Admitindo a importância da literatura não canônica para compreensão das comunidades cristãs das origens, (1) apresentar-se-á, através dos Atos Apócrifos, a maneira como as comunidades cristãs narrativizavam suas identidades em diálogo com o mundo do Mediterrâneo, muitas vezes subvertendo seus discursos; (2) mapear-se-ão seus discursos ficcionais e as memórias preservadas. Assim, a proposta do artigo é descrever estratégias narrativas e perceber as construções identitárias e ficcionais. Mesmo que correndo o perigo de ser demasiadamente descritivo, as indicações das estratégias discursivas servem como avaliação da contribuição dessa literatura. Ainda, como nos interessam as forças ficcionais, quanto mais mirabolantes, criativas e não especializadas forem as narrativas, mais reveladoras e importantes serão para a compreensão de como pensavam o mundo e suas nuanças.

\section{Atos Apócrifos e a questão canônica}

Não é o principal interesse deste artigo discutir o gênero prákseis ou acta, mas são relevantes algumas informações sobre esse ponto, mesmo que não caiba aprofundar o assunto. ${ }^{8} \mathrm{O}$ estilo, a forma e a estrutura dessas obras ficcionais lembram a literatura greco-romana tendo como função principal a "propaganda religiosa". Suas narrativas possuem o mesmo estilo de textos como Quéras e Calírroe, Leucipa e Clitofonte, As efesíacas, As etiópicas e As babilônicas. Tanto no romance antigo como nos Atos há ênfase nas aventuras, provações, nas viagens e no maravilhoso. ${ }^{10}$ Perkins

6 MACDONALD, Dennis R. Introduction: The Forgotten Novels of The Early Church. Semeia, n. 38, p. 1-6, 1986b. p. 3.

7 NOGUEIRA, Paulo A. de S. Tradução do intraduzível: a semiótica da cultura e o estudo de textos religiosos nas bordas da semiosfera. Estudos de Religião, n. 29/1, p. 102-126, 2015.

8 Para uma melhor discussão sobre a questão do gênero literário e os Atos Apócrifos dos Apóstolos, cf. MACDONALD, D. R. Which Came First? Intertextual Relationships among the Apocryphal Acts of the Apostles. Semeia, n. 80, p. 9-40, 1999.

9 PERVO, R. I.; ATTRIDGE, H. W. Acts: A Commentary on the Book of Acts. Minneapolis: Fortress, 2009. (Hermeneia - a critical and historical commentary on the Bible). p. 58.

10 PERKINS, 1995. 
assinala que os Atos Apócrifos são textos de cunho popular e revelam-se como escritos por e para espaços não sofisticados, o que possibilita ouvir vozes populares das comunidades cristãs dos primeiros três séculos. ${ }^{11}$ Como obras que circulavam, os Atos Apócrifos estabeleciam diálogo com outros textos e serviam como fontes de imaginários na cultura. Podemos, então, afirmar que suas imagens, ritos, mitos, lendas, práticas etc. se estabeleciam no imaginário dos grupos cristãos. As imagens dos Atos Apócrifos na cultura revelam uma crítica social e, ao mesmo tempo, servem como construção das fronteiras identitárias.

O adjetivo canônico foi usado pela primeira vez referindo-se aos livros bíblicos no Concílio de Laodiceia (360) e na carta pascoal de Atanásio, em 367. A palavra cânon, como catálogo de livros bíblicos reconhecidos, começa a ser usada na igreja latina pelos meados do século IV. ${ }^{12}$ Dessa forma, essa expressão aplicada à Bíblia tem um primeiro significado de norma de fé e de vida para os fiéis. Além disso, a formação do cânon do Novo Testamento representa, também, a história das crenças das comunidades cristãs e os usos dos textos. Os concílios seriam, então, menos catalogadores do que espaços de reconhecimento de usos. Contudo, a circulação dos muitos outros textos, inclusive os Atos Apócrifos, exige o rompimento das leituras unicamente canônicas, cuja superação possibilita o acesso à multifacetada realidade dos cristianismos das origens, suas complexas dinâmicas sociais, crenças e práticas. Nessa perspectiva, nos últimos anos, os estudos especializados estão avançando em direção à superação do preconceito canônico para preocupar-se com a história do imaginário, as construções de identidade e as estratégias de ficcionalização do mundo das primeiras comunidades cristãs. Como firmamos em outro texto:

A literatura cristã que se desenvolve no contexto da historiografia neotestamentária torna plausível uma aproximação às experiências cristãs no contexto do cristianismo antigo; experiências amplamente variadas em seu caráter étnico-geográfico e plural em seu significado no âmbito das narrativas e do processo interpretativo. Desse modo, tornam-se atraente e pertinente os conceitos como identidades, linguagem, ficção e memória ao tratar o tema ${ }^{13}$.

Dessa forma, essa literatura é uma rica fonte de tradições e lendas a respeito dos apóstolos, assim como de temas, gêneros e liturgias. Os Atos dos Apóstolos tornam-se fontes indispensáveis, ao lado os evangelhos e literatura apocalíptica, para compreensão científica dos cristianismos das origens. Neste artigo, proporemos o

\footnotetext{
11 PERKINS, 1995, p. 125.

12 ARTOLA, J. M. S.; CARO, A. M. A Bíblia e a Palavra de Deus. São Paulo: Ave-Maria, 2011. p. 55.

13 TERRA, Kenner R. C.; IZIDORO, José Luiz. Identidade e memória cultural no Cristianismo Primitivo: novas abordagens das teorias da linguagem. In: CARNEIRO, Marcelo. Bíblia e Cultura. Tradição, tradução e exegese - debatendo as diferenças leituras da Bíblia: conferências e ensaios apresentados no VI Congresso Brasileiro de Interpretação Bíblica. São Paulo: Fonte Editorial, 2014. p. 169.
} 
alargamento do conceito de cânon, levando-o às categorias culturais para demostrar a importância desses textos para a compreensão do cristianismo primitivo. ${ }^{14}$

Como cânon da cultura ${ }^{15}$, os Atos Apócrifos alargam as fronteiras do canônico, permitindo ao pesquisador compreender melhor as memórias, experiências, imaginários, construção de identidade e inversões sociais dos cristianismos das origens e sua relação com o Mediterrâneo.

\section{Atos Apócrifos ${ }^{16}$ e construção de identidade}

A memória é a faculdade que nos permite formar uma consciência de nós mesmos (identidade), individual e coletiva. Um eu humano é a identidade diacrônica, construída com o material do tempo. Essa síntese de tempo e identidade é efetuada pela memória. ${ }^{17}$ Sendo assim, se a memória cultural se revela como conjunto de elementos da cultura (como palimpsesto, organiza-se dinamicamente), seria, então, possível determinar em quais e com quais memórias o texto cria identidades, constrói realidades ou interpreta mundos. Desta forma, as imagens dos textos e seus discursos definem suas potencialidades individuais e coletivas e, especialmente, o outro, como membro de outros conjuntos de memórias, as quais estabelecem alteridades.

Hall afirma que identidade étnica pode somente ser constituída por oposição de outras identidades étnicas. ${ }^{18}$ Essa é formada pelo reconhecimento das distinções entre si, uma distinção autoconsciente. É uma objetivação percebida na compreensão de fundamentos compartilhados de práticas e experiências. Assim, o grupo étnico se estabelece nas interações socialmente situadas, por isso seu caráter fluído, que Hall não cansa de afirmar. O conteúdo cultural da etnicidade pode variar substancial e qualitativamente em diferentes contextos, como também a própria importância da etnicidade. Ou seja, a práxis da etnicidade resulta de múltiplas realizações transitórias da diferença étnica em contextos particulares. Philippe Poutignat, interpretando Frederik Barth, afirma:

Ele entendeu muito bem e faz entender que essa identidade, como qualquer outra identidade coletiva (e assim também a identidade pessoal de cada um), é construída e trans-

14 TERRA, Kenner R. C. El Canon más allá del Canon: Hechos Apócrifos de los Apóstoles. RIBLA, v. 1, n. 73, p. 27-42, 2016. p. 28.

${ }^{15}$ Essa expressão é largamente desenvolvida pelos teóricos da memória Aleida e Jan Assmann. Cf. ASSMANN, Aleida. Canon and Archive. In: ERLL, Astrid; NÜNNING, Ansgar (ed.). Cultural Memory Studies: An International and Interdisciplinary Handbook. Berlin: Walter de Gruyter, 2008a. p. 97-107; ASSMANN, Jan. Collective Memory and Cultural Identity. New German Critique, n. 65, p. 125-133, 1995; ASSMANN, Jan. Communicative and Cultural Memory. In: ERLL, Astrid; NÜNNING, Ansgar (ed.). Cultural Memory Studies: An International and Interdisciplinary Handbook. Berlin: Walter de Gruyter, 2008b. p. 109-118.

${ }^{16}$ As citações das fontes serão feitas a partir de PIÑERO, Antonio; CERRO, Gonzalo del. Hechos Apócrifos de los Apostoles. Madrid: Biblioteca de Autores Cristianos, 2012. v. I, II e III. Seguirei o modelo de citação dos apócrifos comumente utilizado pelos trabalhos científicos.

17 ASSMANN, 2018b, p. 109.

${ }^{18}$ HALL, J. M. Ethnic Identity in Greek Antiquity. Cambridge: University Press, 1997. p. 4. 
formada na interação de grupos sociais através de processos de exclusão e inclusão que estabelecem limites entre tais grupos, definindo os que os integram ou não [...] os traços que levamos em conta não são a soma das diferenças "objetivas", mas unicamente aqueles que os próprios atores consideram como significativos ${ }^{19}$.

A “interação situacional", mecanismo para fluidez da construção da identidade, dentro de interações socioculturais localizadas e históricas, serve como peça fundamental da moderna perspectiva da construção da identidade. Partindo dessas discussões, podemos afirmar que as muitas imagens dos Atos Apócrifos podem se mostrar como crítica social e, ao mesmo tempo, servem como construção das fronteiras identitárias, que são circunscritas em memórias estabelecidas e reapropriadas, as quais delimitam o outro, muitas vezes grotescalizado, e possibilitam a percepção de si e do grupo como agentes da divindade.

São comuns nos Atos Apócrifos as narrativas de envio para lugares longínquos. Há, antes disso, sempre uma divisão orientada por Deus.

Naquela época, estávamos todos os apóstolos em Jerusalém, Simão, que é chamado Pedro e André, seu irmão, Tiago, filho de Filho de Zebedeu e João, seu irmão, Felipe e Bartolomeu, Tomé e Mateus, o publicano, Tiago, filho de Alfeu, e Simão o cananeu, e Judas, irmão de Tiago. E dividimos as regiões do mundo, para que todos fossemos à região que caísse sobre cada um, e à nação para aonde o Senhor nos enviasse (Atos de Tomé 1).

Em Atos de André, Matias é enviado à nação dos canibais; em Atos de Tomé, Tomé é enviado para Índia; para Pedro ficou reservada Roma; Bartolomeu, Licaônia etc. Nos Atos de Filipe, por exemplo, ao chegar a Hierápolis, enfrenta serpentes e dragões. O lugar onde Matias chega, as pessoas não comem pão, mas seres humanos (Atos e André). Pelo que parece, o mitema "viagem" ganha nos Atos Apócrifos o sentido de ir ao desconhecido, o longe, ao outro distante, das extremidades; talvez, a ida ao caos, onde os milagres serviriam para libertação e organização do caótico. Antes de serem históricas, no sentido positivista da expressão, essas narrativas mostram a construção do outro e de si mesmo, na qual os apóstolos estão no centro do mundo enquanto o outro é a desordem, o não lugar, para onde uma viagem só seria possível com a motivação e o impulso divinos, como acontece com o relutante Tomé.

Na tarefa da compreensão de si, os apóstolos não somente representam a identidade individual, mas das comunidades cristãs diante dos povos. Nesse sentido, os discursos encratistas são corriqueiros nos Atos Apócrifos. Em Atos de Paulo e Tecla, Paulo entra na casa de Onesíforo e faz um discurso a respeito da enkrateia e anastáseos (AtPl 5.1). O narrador continua e dá voz a Paulo:

Disse Paulo: "Felizes são os puros de coração, pois eles verão a Deus. Felizes são os que guardam a carne casta, pois eles se tornarão santuário de Deus. Felizes os encratis-

19 POUTIGNAT, Philippe. Teorias da Etnicidade: seguido de grupos étnicos e suas fronteiras de Fredrik Barth. São Paulo: UNESP, 1998. p. 11. 
tas (enkrateîs), pois Deus falará a eles. Felizes são os que renunciam a este mundo, pois eles agradarão a Deus. Felizes são os que têm suas esposas como se não as possuíssem, pois eles se tornarão angeloi Theou (anjos de Deus)" (Atos de Paulo e Tecla 5.2-10).

Mesmo que a expressão "encratista" não represente um movimento estabelecido ou um termo técnico, serve para a percepção da compreensão de si estruturada na dissociação, descontinuidade com o sistema/mundo. A construção narrativa da identidade determina e revela a relação dos seguidores do evangelho com a corporeidade e resulta na percepção de si com negação e enfrentamento direto aos padrões sociais. Como se percebe, o "comum" no enredo e entre os temas nos Atos dos Apócrifos é a pregação sobre a continência sexual, por meio da qual se caracteriza a representação de si do cristianismo e da missão dos apóstolos ${ }^{20}$ Inclusive, os textos falam como essa proposta causa problemas entre as mulheres convertidas e seus maridos ou amantes. Em Atos de Pedro, por exemplo, somos informados de que, por amarem a doutrina da pureza, muitas mulheres deixavam seus maridos, gerando muitas separações em Roma (AtPe 34).

Judith Perkins, em artigo que discute a questão literária dos Atos Apócrifos e do romance grego, defende que o peculiar nos romances e Atos é a relação com as dinâmicas culturais, o que mostra um claro enfrentamento dos Atos não somente ao tema do casamento no romance, mas especialmente sua descontinuidade discursiva com o valor do casamento no mundo romano. ${ }^{21} \mathrm{O}$ romance grego revela-se como o contexto para a compreensão da ênfase na rejeição ao casamento nos Atos dos Apóstolos. A rejeição nos Atos ao casamento muda tanto a afirmação desse tema nos romances gregos como também na estrutura social de seu tempo. Por isso os Atos Apócrifos incorporam uma mensagem antissocial. Por meio de sua rejeição à união conjugal e as implicações dessa proposta, os Atos apresentam uma proposta de fim da existência da sociedade no modelo de seus dias. Eles são hábeis para investir suas narrativas com esse sentido radical mediante a inversão intertextual da representação do casamento e castidade dos romances gregos. Em sua total rejeição do sexo na sociedade humana, os Atos Apócrifos referem-se implicitamente ao que eles excluem. Sua representação do sexo e casamento adquire significado e providencia a imagem inversa da equação entre casamento e sociedade construída pelo romance grego. Se o romance celebra a sociedade e seu futuro através do trópico do casamento, o retrato nos Atos Apócrifos repudia qualquer confiança na estrutura social dominante. Por meio de sua rejeição ao sexo e casamento, os Atos rejeitam a operação da estrutura social e instituições.

Depois de citar narrativas dos Atos Apócrifos que mulheres aceitam, pós-conversão, a separação e dedicação austera, Virginia Burrus descreve a construção das fronteiras do corpo feminino, mas que revela, ao mesmo tempo, as fronteiras da identidade percebida pelas comunidades cristãs. Ela demonstra que em todas as histórias está claro que o lugar da mulher é no interior da casa de seu marido, enquanto o ma-

\footnotetext{
${ }^{20}$ PERKINS, Judith. The World or Another? The Intertextuality of the Greek Romances, the Apocryphal Acts and Apuleius' Metamorphosed. Semeia, n. 80, p. 245-260, 1999. p. 249.

21 PERKINS, 1999, p. 250.
} 
rido movimenta-se no exterior, no mundo público. Permanecendo em casa, a mulher aceita seu lugar na sociedade, casamento e relacionamento sexual. Todas as vezes que ela sai de casa, atravessa fronteiras e entra no mundo masculino, provocando desaprovação, hostilidade e suspeita. Quando, inevitavelmente, ela desafia a fronteira física de sua esfera, também desafia as fronteiras sociais e sexuais, sobretudo as fronteiras do casamento patriarcal. ${ }^{22}$ Desta forma, a pregação e proposta de inversão e ascetismo nos Atos Apócrifos, tanto dos gêneros como das práticas sociais, demonstram a compreensão da identidade das comunidades cristãs em conflito com o mundo e estrutura social de seu tempo, que tem em suas bases a família patriarcal.

O próprio poder sobrenatural na realização das ações mais mirabolantes serve como identificação de empoderamento, inclusive em combate direto com outras práticas religiosas e poderes governamentais. Preservando e potencializando narrativas de exorcismo e milagres em geral, os textos descrevem os apóstolos como figuras especiais e típicas epifanias, as quais revelam a maneira como se percebem no mundo e criam as fronteiras identitárias: eles (mundo, governo humano, natural), eu/ nós (não mundo, governo celestial, sobrenatural). As muitas narrativas de martírio nos Atos Apócrifos mostram, de igual modo, enfrentamento aos governos humanos e sua expectativa de relação com as realidades não históricas.

\section{Ficção da realidade e as estratégias narrativas dos Atos Apócrifos}

Wolfgang Iser sugere que a obra literária excede o mundo real que ela incorpora. Consequentemente, por isso não é surpresa que a ficção literária frequentemente tenha sido estigmatizada como falsidade. ${ }^{23}$ Ficção e ficcionalização, segundo Iser, vinculam uma dualidade. Podemos falar em duas maneiras de duplicação, duas formas para sobrepor a realidade: a mentira e a ficcionalização. Iser explica muito bem a diferença desses dois termos:

O mentiroso deve ocultar a verdade, que está potencialmente presente na máscara que a esconde. Nas ficções literárias, os mundos existem se sobrepondo e, embora eles sejam individualmente reconhecidos, estão postos em um contexto não familiar. Portanto, a mentira e a literatura sempre contêm dois mundos: a mentira incorpora a verdade, que é a razão pela qual a verdade precisa ser escondida; as ficções, por outro lado, incorporam uma realidade identificável, sujeita a uma remodelação imprevisível. Assim, quando descrevemos a ficcionalização como um ato de sobreposição, devemos ter em mente que a realidade sobreposta não é colocada de lado: ela se mantém presente, por isso impregna a ficção com uma dualidade explorável para diferentes propósitos ${ }^{24}$.

22 BURRUS, V. Chastity as Autonomy: Women in the Stories of the Apocryphal Actos. Semeia, n. 38, p. 101-116, 1986. p. 111.

${ }^{23}$ ISER, Wolfgang. Fictionalizing: The Anthropological Dimension of Literary Fictions. New Literary History, n. 21/4, p. 939-955, 1990. p. 939.

${ }^{24}$ ISER, 1990, p. 941. 
Por conseguinte, a literatura cria mundos a partir da realidade identificável. A expressão "remodelar" é uma palavra-chave, pois descreve a criação, quando o mundo é transbordado, gerando o que ele chama de dualidade. Criam-se novos mundos não do nada, mas do experimentado. Na ficção literária, a existência é excedida. É por isso que descrevemos a ficcionalização como um ato de "excesso". Aqui devemos indicar, então, a relação da memória cultural e o conceito de imaginário, como conjunto de representações mentais de indivíduos e grupos, as quais a literatura preserva e pelas quais pensa a realidade, comunicando-a e transformando-a.

Os Atos Apócrifos ficcionam o mundo. Suas narrativas representam a dualização do mundo greco-romano, o qual é transbordado e criativamente subvertido. No mundo ficcionado dos Atos Apócrifos, os embates com lideranças imperiais e seus súditos são ladeados por militância contra forças punitivas, anjos de fogo, demônios feios ou energias impuras, como encontramos nos Atos de André.

Em Atos de Pedro, por exemplo, a mulher de Albino, um amigo de César, afastava-se do seu marido, negando-lhe relações sexuais, e frequentava a casa de Pedro. $\mathrm{O}$ texto diz que Albino enfureceu-se contra Pedro como uma besta. Não é por acaso que usa-se a expressão "besta" ou "fera" (AtPe 33), pois o tema do enfrentamento de animais bestiais, feras e forças malignas são recorrentes. Enfrentar expressões sociais contrárias ao discurso dos apóstolos é continuidade, em um mundo duplicado, das lutas contra as forças malignas e monstruosas. O espetáculo das arenas, dos teatros e dos festins é traduzido para as narrativas mostrando continuidade entre as realidades monstruosas e as forças sociais.

Na ficção literária dos Atos Apócrifos, os animais relacionam-se com os discípulos como forças domesticáveis. Nas mãos dos inquisidores, são instrumentos de punição, mas quando enfrentam Tecla ou Paulo, por exemplo, passam de feras indomáveis a protetores e batizados.

Depois de resistir ao ataque de Alexandre, rasgando sua roupa e derrubando sua coroa, Tecla foi levada perante o governador de Icônio, o qual a condenou às bestas (Atos Paulo e Tecla 27). A Narrativa da "luta" de Tecla e as bestas é detalhada e revela a criação de uma realidade na qual animais e seres humanos estão em contato racional e disputa de poder, o que seria uma continuidade da querela com Alexandre.

Quando as bestas eram conduzidas em procissão, eles a amarraram a uma leoa feroz, e a rainha Trifena a acompanhava. Mas a leoa, com Tecla assentada sobre ela, lambia seus pés e toda a multidão ficou surpreendida [...]. Quando, após a sua exibição, Trifena a recebeu, ao mesmo tempo lamentava por Tecla ter que enfrentar as bestas no outro dia [...]. Tecla, tirada das mãos de Trifena, foi despida, colocaram-lhe uma cinta e jogaram-na no estadium. Os leões e os ursos foram contra ela e uma leoa selvagem correu em sua direção e deitou-se a seus pés. A multidão de mulheres, por sua parte, gritava mais alto. Então, um urso a atacou, mas a leoa enfrentou-o e o rasgou em pedaços. Novamente, um leão, que foi treinado para enfrentar homens e que pertencia a Alexandre, avançou contra Tecla, mas foi enfrentado pela leoa, que morreu junto com ele. Então, as mulheres choraram ainda mais, pois a leoa, sua protetora, morreu. Então, eles soltaram muitas bestas e ela ficou de pé com as mãos erguidas, e orava. Quando ela terminou a oração, virou-se e viu um grande buraco cheio de água e disse: "Agora é tempo para eu 
me lavar!" Ela jogou-se dizendo: "Em nome de Jesus Cristo, eu me batizo no meu último dia". Quando as mulheres viram isto, choraram, e com toda a multidão, disseram: "Não se lance na água!". O governador também chorou, porque as focas devorariam tal formosura. Então, ela lançou-se na água em nome de Jesus Cristo e as focas viram o resplendor de um raio de fogo e caíram mortas. Porém, ao redor de Tecla havia uma nuvem de fogo para que as bestas não a tocassem e para que ninguém visse a sua nudez (Atos de Paulo e Tecla 28-34).

Esse domínio sobrenatural do mundo, que é animado pela palavra e intervenções divinas, está sob orientação dos heróis das narrativas. Tecla doma bestas, coloca aos seus pés feras e é salva da fome de algumas focas por meio de raios, as quais são seres do desconhecido, do grotesco. O mundo é perpassado por uma relação interacional entre seres racionais e irracionais. Se Tecla está sob orientação da divindade criadora dos céus e terras, os animais somente serão uma ameaça se estiverem do lado das forças bestiais dos poderes contrários à sua pregação e seu ascetismo. Bestas e seres humanos compõem uma realidade ficcionada, na qual há estreitas relações. Nesse mundo dualizado da narrativa, Tecla é agente de Deus e por ele pode dominá-lo. Nos Atos Apócrifos, o palco das disputas dos apóstolos e dos cristãos não é um mundo de funcionamentos somente histórico-sociais, mas esse é discursivizado e animado por forças caóticas e divinas.

A continuidade da narrativa de Paulo e Tecla é impressionante. A reação do governador é a mesma das bestas: curva-se ao poder revelado em Tecla. Ele fica estupefato e entra em um diálogo com aquela mulher com poder para domesticar animais perigosos: "O governador chamou Tecla do meio das bestas e disse-lhe: 'Quem és tu? O que há em ti que nenhuma das bestas te tocou?"' (Atos Paulo e Tecla 37). A resposta de Tecla revela o poder propagandístico e revelatório desses sinais milagrosos:

Eu sou uma serva do Deus vivo, e quanto ao que há em meu redor, eu creio no Filho em quem Deus se agrada, por isso nenhuma das feras me tocou. Pois somente Ele é o caminho da salvação e o fundamento da vida eterna. Aos que foram atingidos por tempestades, Ele tornou-se um refúgio; aos que sofrem perseguições, alívio; aos desesperados, abrigo. Em uma palavra, aquele que não crer nele, não viverá para sempre (Atos de Paulo e Tecla 37).

O mundo da narrativa é interligado diretamente às forças cósmicas e celestiais. Os que se filiarem a este mundo e escolherem pelo deus proclamado poderão ser identificados como filhos de Deus e experimentarão as benesses dessa divindade. $\mathrm{O}$ mundo é dividido em dois lados, que estão em conflito. No texto, o governador, ao ouvir a pregação, mandou trazer roupas para Tecla. E o diálogo continua:

"Coloque esta roupa." Tecla disse: "Aquele que me vestiu quando estava nua entre as feras, Ele me revestirá de salvação no dia do Juízo". E tendo recebido as vestes, vestiu-se. O governador emitiu, imediatamente, um edito, dizendo: "Tecla, a temente serva de Deus, eu a liberto para vocês". E todas as mulheres gritaram bem alto, em uníssono, deram louvor a Deus, dizendo: "Há apenas um Deus, o que salvou a Tecla!". E as bases da cidade se estremeceram com suas vozes (Atos de Paulo e Tecla 38). 
Monstros, animais, demônios, homens e poderes governamentais são como forças paralelas, com os quais os apóstolos estão em conflito. A realidade é ficcionada, transbordada e representa um mundo no qual todos esses poderes se rendem à pregação legitimada pelas ações miraculosas. Nas narrativas preservadas nos manuscritos de Vercelli dos Atos de Pedro, por exemplo, o mundo é intensamente impregnado de potencialidades mágicas, as quais podem entrar em embates, demonstrando a magia cristã como o centro. Na mesma obra, cachorros falam, peixe morto nada feliz na água como se estivesse vivo, pessoas voam, mostrando como a realidade é duplicada ficcionalmente para construção de uma realidade animada, misteriosa e cheia e intervenções sobrenaturais, as quais são facilmente dominadas e articuladas pelos heróis das narrativas.

Assim, ficção nos Atos não destorce a realidade, mas lhe dá sentido. O mundo é visto como palco de forças humanas que são vencidas, como são as sobrenaturais, com uma temporalidade que não está estabelecida simplesmente pelo desenvolvimento histórico, mas por intervenções do divino. O mundo torna-se um palco de forças, onde se enfrentam e invertem as relações sociais estabelecidas, o que significa vencer as forças bestiais e animalescas.

\section{Considerações finais}

Os Atos Apócrifos são textos carregados de imagens que para o leitor moderno seriam caracterizadas como "grotescas", "esdrúxulas" ou dogmaticamente não sintonizadas com as expressões teológicas comumente aceitas. Além dessa rápida e, também, preconceituosa avalição, seu caráter apócrifo aprofunda ainda mais sua negativa valoração. Em uma perspectiva historiográfica tradicional, somente os textos do centro ou os grandes manuais seriam fonte fidedigna para as pesquisas dos cristianismos antigos, por vezes apresentado como um movimento monolítico e unívoco. Essa perspectiva metodológica acaba destituindo textos como os Atos Apócrifos da categoria de objetos aceitáveis para compreensão das primeiras comunidades cristãs. Contudo, como foi defendido aqui e por outros pesquisadores, alargar as fontes para além dos "grandes textos", ou canônicos, permite-nos novos horizontes: (1) demostrar a pluralidade de cristianismos, o que possibilitará ouvir vozes lançadas para as margens do cânon oficial; (2) acessar imaginários e compreensão de mundos de outros grupos cristãos "não canônicos"; (3) com as viagens, pregações, milagres e lendas, é possível acessar a representação de mundo das primeiras comunidades cristãs; (4) e revelam a narrativização das identidades cristãs no segundo e terceiro séculos.

As pesquisas bíblicas, pelo menos no Brasil, dão passos tímidos em direção às pesquisas desse material. Contudo, precisamos alargar as fronteiras do canônico para termos um acesso mais amplo à maneira como os primeiros cristãos pensavam a si mesmos, o mundo, o outro, as forças do império etc. Por isso novas perspectivas, especialmente historiográficas, precisam ser aplicadas à documentação cristã primitiva, as quais deem conta da complexidade desses materiais. 


\section{Referências}

ASSMANN, Aleida. Canon and Archive. In: ERLL, Astrid; NÜNNING, Ansgar (ed.). Cultural Memory Studies: An International and Interdisciplinary Handbook. Berlin: Walter de Gruyter, 2008a.

ASSMANN, Jan. Collective Memory and Cultural Identity. New German Critique, n. 65, p. 125-133, 1995.

. Communicative and Cultural Memory. In: ERLL, Astrid; NÜNNING, Ansgar (ed.).

Cultural Memory Studies: An International and Interdisciplinary Handbook. Berlin: Walter de Gruyter, 2008b.

BURRUS, V. Chastity as Autonomy: Women in the Stories of the Apocryphal Actos. Semeia, n. 38 , p. 101-116, 1986.

HALL, J. M. Ethnic Identity in Greek Antiquity. Cambridge: University Press, 1997.

ISER, Wolfgang. Fictionalizing: The Anthropological Dimension of Literary Fictions. New Literary History, n. 21/4, p. 939-955, 1990.

JÚNIOR, Paraízo. O Pedro ulterior: uma discussão axiológica a partir da tradução do Apócrifo Atos de Pedro. 2014. 498 f. Tese (Doutorado em Estudos da Tradução) - Centro de Comunicação e Expressão, Universidade Federal de Santa Catarina, Florianópolis; Belo Horizonte, 2014. LE GOFF, Jacques. História e memória. 2. ed. Campinas: Unicamp, 1992.

MACDONALD, D. R. Which Came First? Intertextual Relationships Among the Apocryphal Actos of the Apostles. Semeia, n. 80, p. 9-40, 1999.

The Actos of Andrew and Mathias and the Actos of Andrew. Semeia, n.38, p. 9-25. 1986a. Introduction: The Forgotten Novels of the Early Church. Semeia, n. 38, p.1-6, 1986b.

Which Came First? Intertextual Relationships Among the Apocryphal Actos of the Apostles. Semeia, n. 80, p. 9-40, 1999.

NOGUEIRA, Paulo A. de S. Tradução do intraduzível: a semiótica da cultura e o estudo de textos religiosos nas bordas da semiosfera. Estudos de Religião, n. 29/1, p. 102-126, 2015.

PERKINS, Judith. The Suffering Self: Pain and Narrative Representation in the Early Christian Era. London; New York: Routledge, 1995.

. The World or Another? The Intertextuality of the Greek Romances, the Apocryphal Acts and Apuleius' Metamorphosed. Semeia, n. 80, p. 245-260, 1999.

PERVO, R. I.; ATTRIDGE, H. W. Acts: A Commentary on the Book of Acts. Minneapolis: Fortress, 2009. (Hermeneia - a critical and historical commentary on the Bible). p. 58.

PIÑERO, Antonio; CERRO, Gonzalo del. Hechos Apócrifos de los Apóstoles. Madrid: Biblioteca de Autores Cristianos, 2012. v. I.

POUTIGNAT, Philippe. Teorias da Etnicidade: seguido de grupos étnicos e suas fronteiras de Fredrik Barth. São Paulo: UNESP, 1998.

ROBERTS, A.; DONALDSON, J.; COXE, A. C. The Ante-Nicene Fathers. Translations of the writings of the Fathers down to A.D. 325. Latin Christianity: Its Founder, Tertullian. Oak Harbor: Logos Research Systems, 1997. v. III.

SCHNEEMELCHER, W. New Testament Apocrypha. Kentucky: Westminster John Knox, 1992. v. 2. STOOPS, R. F. Jr. Patronage in the Actos de Peter. Semeia, n. 38, p. 91-99, 1986.

TERRA, Kenner R. C.; IZIDORO, José Luiz. Identidade e memória cultural no Cristianismo Primitivo: novas abordagens das teorias da linguagem. In: CARNEIRO, Marcelo. Bíblia e Cultura. Tradição, tradução e exegese - debatendo as diferenças leituras da Bíblia: conferências e ensaios apresentados no VI Congresso Brasileiro de Interpretação Bíblica. São Paulo: Fonte Editorial, 2014. 